\title{
The Dark Inside the Prologue : Enactive Cognition and Eerie Ontology in Catherynne M. Valente's Radiance
}

\section{Polvinen, Merja}

2021-09

Polvinen, M 2021 , ' The Dark Inside the Prologue : Enactive Cognition and Eerie Ontology in Catherynne M. Valente's Radiance ', Style , vol. 55 , no. 3 , pp. 385-405 . https://doi.org/10.5325/style.55.3.0385

http://hdl.handle.net/10138/338539

https://doi.org/10.5325/style.55.3.0385

cc_by

acceptedVersion

Downloaded from Helda, University of Helsinki institutional repository.

This is an electronic reprint of the original article.

This reprint may differ from the original in pagination and typographic detail.

Please cite the original version. 
Author Accepted Manuscript - PLEASE DO NOT CITE WITHOUT CONTACTING THE AUTHOR

Uncertain Ontologies in 21st-Century Storyworlds

Style Special Issue, co-edited by Lieven Ameel and Marco Caracciolo

Merja Polvinen

Swedish Collegium for Advanced Study / University of Helsinki

merja.polvinen@helsinki.fi

\section{The Dark Inside the Prologue: \\ Enactive Cognition and Eerie Ontology in Catherynne M. Valente's Radiance}

\section{Introduction}

As the contributions to this special issue show, the "earnest ontologies" of $21^{\text {st }}$-century fiction continue to examine the ontological instabilities of postmodernism, even as they also turn to reengage with real-world concerns (see Introduction to this issue). In doing so, these works attempt to hold on to the idea of multiple, flickering realities, but at the same time they aim to change the tone with which that idea is approached and represented. Contemporary literature is therefore rethinking the metaphor of flickering realities by adding embodied and communicative dimensions to the postmodernist imaginary. This article analyzes Catherynne M. Valente's Radiance (2015), a novel that takes the flickering, shimmering ontology of contemporary fiction as its self-reflective theme. Set within an interplanetary film industry where the dream factories of Hollywood have decamped to the Moon, Valente's novel falls under the genre of speculative fiction. The storyworld also includes the infinite quantum multiverse, which traps the protagonist in a superposition between many realities. While that suspension resembles the anxieties of postmodern ontologies, this novel, just as many other $21^{\text {st }}$-century works, differs from its postmodernist predecessors in its earnest engagement with the human ability to create and communicate imagined realities.

In this article, I approach uncertain literary ontologies from the direction of cognitive literary studies - specifically the literary applications of "enactive" cognition. Enactive cognition, as described by Francisco Varela, Evan Thompson, and Eleanor Rosch in The Embodied Mind in 1991, was conceived as an embodied and phenomenologically aware alternative to mainstream cognitive science. It presents cognition as a process of sense-making built on autopoiesis; as a dynamic relationship between a life-form and its environment. Thus, enactive cognition can be seen as a contemporary expression of the phenomenological notion of an individual cognizer being entangled with their environment: that "the world is inseparable from the subject, but from a subject 
who is nothing but a project of the world; and the subject is inseparable from the world, but from a world that it itself projects" (Merleau-Ponty 454; see also Di Paolo). My focus here will be on that entanglement, and on its consequences both to the ontologies of post-postmodernist fiction and to fictional worlds as they are conceived in cognitive literary theory. Central to this argument is the point, also made by Marco Caracciolo in this special issue, that just as much as phenomenology, enactive cognition involves us in unsettling the dichotomy between ourselves and world. ${ }^{1}$ The ontological instabilities of $21^{\text {st }}$-century literature thus offer a particularly fertile soil for enactive theorizing, as both the fictions and the theory aim to query the idea of world as a coherent ontological whole that exists on the outside of the perceiving subject. At the same time, both also respect embodied experience and the entanglement of the perceiving self in the physical world. This combination of ontological groundlessness and bodily entanglement is explicitly thematized in Valente's novel.

\section{The Reconstructive Fantastic}

When Brian McHale defined postmodern literature as displaying the ontological dominant (as opposed to the epistemological one of modernism), he also laid out a series of questions that such literature sets out to explore:

What is a world?; What kinds of world are there, how are they constituted, and how do they differ?; What happens when different kinds of world are placed in confrontation, or when boundaries between worlds are violated?; What is the mode of existence of a text, and what is the mode of existence of the world (or worlds) it projects?; How is a projected world structured? (Postmodernist Fiction 10)

As made clear by McHale's analyses of the works by e.g. Thomas Pynchon, Donald Barthelme, or William Burroughs, the worlds of postmodern literature tend to be plural, unstable and constituted by our own perception. These fragmentary and often nightmarish worlds, as well as the metaleptic movement of authors and characters across the borders separating those worlds, exemplified by Flann O'Brien's At Swim-Two-Birds (see the discussion in Bell and Alber 169-175), aimed mainly to break exactly the thing that narrative fiction was supposed to be good at: the creation of a believable world in which readers could immerse themselves.

As postmodernism waned as an artistic movement, new attempts at dealing with the same ontological precariousness appeared, including what Irmtraud Huber has called "reconstructive

\footnotetext{
${ }^{1}$ Pieter Vermeulen's article in this issue also discusses the idea of environmental entanglement of the human, but where my focus here is on enactive cognition, he follows the history of the concept through French theory and écriture.
} 
fantasies": works that aim to repurpose the instability at the heart of postmodernism. Tzvetan Todorov's seminal definition sees the fantastic as a hesitation between natural and supernatural explanations for the story events - a hesitation which may or may not be experienced by the characters, but which definitionally must be there for any reader that has been integrated into the fictional world (Todorov 31-32). ${ }^{2}$ McHale points out how Todorov's fantastic is finally an epistemological rather than ontological hesitation, but then extends the same idea first to the postmodernist "flickering" between "this world and the world next door" (75), and second to hesitations that take place in the acts of representation that make up the artwork; between "the representation of a world and the anti-representational foregrounding of language for its own sake" (82-83). However, as the 21st-century fantastic moves away from the postmodernist emphasis on the opposition between the fictional world and its artifice, McHale's description of the meta-level flickering as "anti-representational" also needs adjustment. ${ }^{3}$ In her discussion of reconstructive fantasies Huber suggests a new form of duality in the fantastic specific to $21^{\text {st }}$-century literature; one that rolls both the epistemological and the ontological hesitations discussed by Todorov and McHale onto the next level. Reconstructive literature, Huber argues, aims to promote the value of the purposefully fictive, and thus makes fantastic hesitation serve a "pragmatic," communicative purpose (8-10, 55-61). Such self-reflective fiction-Huber's examples include Mark Z. Danielewski, Jonathan Safran Foer, Michael Chabon and David Mitchell— “is no longer centrally concerned with unmasking, dissolving, subverting and unsettling, but sets out to gradually displace postmodernism's fantastic paranoia by attempts to reconstruct, (re-)connect, communicate and engage" (24). In order to do so, the reconstructive fantastic takes the dismantling of mimesis as a given, and rather than continuing the postmodern questioning of what this might mean to our understanding of realities, sets out to promote a "perceivable reinvigoration in the belief of the power of fiction" (Huber 41). This pragmatism of 21st-century fantastic appears as an interest in the rhetorical effects of fiction: the reconstructive mode aims both at communicating a world and interacting with reality, even as it continues the postmodern project of ontological hesitation and resistance to mimesis (Huber 12-13).

It is this new mode of reconstructive ontological hesitation that I believe enactive cognition can help to describe. Why would post-postmodernist authors turn to the fantastic to stage their play

\footnotetext{
${ }^{2}$ Todorov's definition has been criticised for focusing on an effect that only occurs within a very few works, and which usually fades by the end of the book "as the ontological riddle is resolved one way or the other, either by confirmation of the supernatural or by a rational explanation" (Huber 56). As a definition of the fantastic it nevertheless continues to exert influence, even in discussions about popular fantasy literature, where no ontological hesitation occurs (Attebery 89).

${ }^{3}$ In its emphasis on embodied perception and the simultaneity of perspectives the flickering of reconstructive fantasy thus resembles Deleuze's "fold," as discussed by Lieven Ameel in this issue.
} 
with a multitude of realities, if their aim is not to show that all realities are constructed illusions? How can they dismantle ontological borders between realities and yet commit themselves to a seemingly naïve sincerity in their willingness to communicate those realities? In cognitive literary studies, the assumption that it is crucial for readers to experience a sense of immersion in a coherent fictional reality has had a strong influence. The ontology of fictional worlds is most often conceptualized either through possible worlds theory or embodied accounts of the narrative imagination. Possible worlds theory, like most theories based on analytic philosophy, is at root disembodied, whereas those approaches that evoke embodied or enactive cognition tend to do so specifically to examine the effects of immersion: how readers use their experience of the real world to imagine a vivid fictional one, and how the empirical reality fades away from experience during reading. ${ }^{4}$ In cognitive discussions, therefore, the experience of the instability of fictional environments has not attracted much attention (but see Bernaerts; Caracciolo "Ungrounding” and "Weird Shimmers"). Here I want to connect that instability of fictional worlds with enactive cognition, and thereby bring the artificiality of fiction more the foreground in cognitive literary studies. In claiming our experience of literary worlds to be primarily a cognitively natural process of straightforward perception of a fictional world means that the process of readerly inference and engagement with the artwork is sidelined. As Richard Walsh puts it, if we theorize fictions as worlds, as "ontological wholes," we make it difficult for ourselves to speak of the rhetorical qualities of fictions on the same level as their worldness (Walsh 401). Enactive cognition, I suggest, offers a way of incorporating the rhetorical qualities of fictions into cognitive studies of fictional worlds without losing sight of embodiment or the sense of an immersive environment.

\section{Enacted Environments}

The so-called "second generation" of cognitive science - also known as 4e-theories of the mindconceptualizes cognition as embodied, embedded, enactive, and extended, and thus distances itself from the representational and computational paradigms of cognition (Newen, Gallagher and De Bruin). Embodiment asks us to abandon the old cognitive science metaphor of the mind as a computer and to include our full sensorymotor system and the body's hormonal traffic as parts of the thinking being; embeddedness asks us to also take into account how the surrounding world impinges on that thinking body; and the extended mind paradigm goes further to claim that not only does the world affect our cognition, but that in using parts of it in our thinking, our mind in fact

\footnotetext{
${ }^{4}$ For a more detailed discussion, see Polvinen ("Enactive Perception").
} 
extends beyond the limits of our own bodies. The embodiedness and the embeddedness of cognition seem fairly accessible as ideas - even if they are not accepted everywhere in the cognitive science community - and the extended mind is most famously explained through the thought experiment featuring the memory-impaired Otto, who finds his way to the Museum of Modern Art by consulting the information he has written down in his notebook (Clark and Chalmers). According to the extended mind paradigm, in this action Otto's cognition extends out beyond his brainbody and into the world, and his mind is taken to exist in the space between his embodied brain and the notebook. It is through such scenarios that the extended mind paradigm tries to get past the preconceptions we have about what the mind and the world are, and to make sense of what the theory might mean to an ordinary, embodied individual human.

The fourth "e," the enactive cognition already discussed by Marco Caracciolo in this issue, sees a deep continuity between the kind of abstract cognition humans engage in and the most basic processes of life itself - in effect claiming that life is a form of cognition (Varela, Thompson and Rosch). Both life and thought are dependent on the creature both separating itself from its environment, and on it existing together with the environment that maintains it, leading to such physical processes as metabolism or niche-construction. Secondly, for the enactive paradigm, not only is cognition not just in the head, or in the whole body of the creature, or extended into the tools around it is able to use, but both the cognizing creature and its environment are co-constituted in their mutual coupling. As Evan Thompson puts it: “a cognitive being's world is not a pre-specified, external realm, . . but a relational domain enacted or brought forth by that being's autonomous agency and mode of coupling with the environment" (407). Or in the words of Ezequiel Di Paolo: "The intimate relation that develops historically between agent and environment is one therefore of mutual shaping" (89). The action from which enactive theory takes its name is thus not just action that has an impact in the world, but instead the action is constitutive: it "brings forth" the world just as it also produces the cognizer itself.

Such a view of the dynamic organism-environment coupling has its roots in the idea of autopoiesis (Maturana and Varela): of life being constitutionally an act of balancing out two opposing trends of "self-production," or taking in elements from the environment for consumption, and "self-distinction," or maintaining a separation between self and world (Di Paolo 80-86). This maintenance is always precarious, and it depends on constant action by the living creature (see also Caracciolo's discussion of the "ontological precariousness of the human" in this issue). That action, for its part, depends on the kind of an environment that surrounds the creature-whether it is one that offers plentiful energy resources for self-production, or dangers that threaten the selfdistinction. The qualities of the environment that set the possibilities for action are in enactive 
theory called affordances. This term derives from the ecological psychology of James J. Gibson, who argued already in 1979 that, for example, visual perception should always be thought of as an action involving the whole body, and to include "the eyes in the head on a body supported by the ground, the brain being only the central organ of a complete visual system" (Gibson 1). This fully embodied perceiver moves through a world that opens to exactly the kind of perception that such a creature is capable of carrying out. "Perceptual experience reveals not the value-neutral world of physics but rather a set of potentials for action," notes Jonathan Kramnick. "To perceive something - anything really — is to reach out to what some part of the world affords for a creature of a certain shape and with certain motility" (10). Thus an affordance "is both an external phenomenon covered by the laws of nature and a potential for action held from a point of view" (Kramnick 11). Thus the world presents itself to us only as far as we are able to recognize its affordances, making each experience of the world dependent on the cognitive and perceptual capacities we have. Gibson's own initial example of an affordance is the ground, which, due to being relatively flat and rigid in relation to the size of an animal, is "stand-on-able, permitting an upright posture for quadrupeds and bipeds. It is therefore walk-on-able and run-over-able. It is not sink-into-able like a surface of water or a swamp" (Gibson 127). However, as the qualities that define a "walk-on-able" surface for any individual species depend as much on the qualities of the species as on those of the surface, Gibson also notes how for water bugs the affordances of water do support for walking (127), and thus even the surface that "grounds" our metaphors for stability and support takes on a relative definition and loses its objective coherence (see also Caracciolo "Ungrounding" 117-119). Finally, the world of affordances is not only relative to the qualities of a species, but it is never stable even for the individual. Instead, it is a dynamical environment that each individual action modifies, from the human act of intentionally shaping material into an object (e.g. to create an effective affordance for hitting something) to the simple fact of breathing, which changes the composition of the air around us.

Situatedness, skilled intentionality, the world affording actions and presenting itself as something; the cognizer being concern-ful and bringing forth its own reality, or laying down a path in walking; the evocative phrases that recur in presentations and applications of enactive cognition point towards the difficulty of verbalizing what exactly the enactiveness of enactive cognition means. Since the enactivist aim is to step beyond a weak sort of causal dependency between the human mind and the physical environment that feeds us with sensation and information, many of the regular expressions of being and moving in a world do not do the job, as they imply either a clear separation between the world and the cognizer, or because the kind of interaction they suggest is causal rather than constitutive. With its neologisms enactive theory aims to dismantle the sense, 
intuitive to many trained within the dualist systems of Western thought, that the border between ourselves and the world is a separation between a solid thing and some space it exists in. Instead, the existence of the world is entangled with our own actions (Hodder), and conversely, the world impinges on us and on our cognitive-embodied existence in a way that may feel uncomfortably like a violation of our own ontological borders. My suggestion is that this conceptualization of our relationship with reality is eerie: that enactive theory gives us a sense of the world having strange agency as well as lacking proper solidity. According to Mark Fisher, the eerie (in contrast to the excess of the weird) is a mode that has at its core a "failure of absence" (there being something where there should be nothing; say, a ghost) and a "failure of presence" (there being nothing where there should be something; e.g. the absence of a familiar, now demolished building) (Fisher 61-64). It is this eeriness of enacted worlds that I suggest is also central to the ontological flickering of postpostmodernist literature. ${ }^{5}$

\section{The Eeriness of Storyworlds}

The eeriness of enactive cognition, I suggest, offers cognitive literary studies a way of talking about the world-like qualities of narrative fictions without closing off their artificial qualities. It does this by emphasizing how the cognizer and the world constitute each other on a level that is not just one of language and complex cultural meanings, but that of the basic processes of self-distinction and self-production of life itself. It offers a way of moving cognitive literary theories away from the container metaphor of a reader being "in" a fictional world and therefore not able to see the communicative purpose of the narrative, and points instead towards ways of thinking of the relationship between reader and fictional world as one where the cognitive environment afforded to the reader consists of qualities drawn from various ontological realms at the same time. Our senses are engaged in the imagining of places, objects and people, but they are also engaged in perceiving the formal elements of the narrative, and the "landscape of affordances" (Rietveld, Denys and Van Vesten 44) we enact in reading includes a world that is and is not there, as well as shapes and rhythms of language and convention that cannot be touched, yet seem to be present.

Enactive cognition may well prove to be useful as a larger theory of reading, but here I want to point out how its combination of eerie absences and presences is particularly useful for looking at

\footnotetext{
${ }^{5}$ I would like to thank Matt Hayler for his presentation on entanglement and enactive theory, titled "Being Beautifully Weird," given at the Cognitive Futures in the Arts and Humanities conference in 2019, which inspired this argument. A further second-generation cognitive take on fantastic hesitation-building on theories of predictive processing - can be found in Kukkonen.
} 
contemporary reconstructive fantasies. Furthermore, in contemporary speculative fiction the fantastic mode can be seen to connect to post-postmodernist ontological attitudes in a way similar to what McHale argued about science fiction and postmodernism in the late $20^{\text {th }}$ century: that they realize "the same underlying principles of ontological poetics" $(60) .{ }^{6}$ One example of how the eerie post-postmodern ontology appears in contemporary speculative fiction is Catherynne M. Valente's Radiance, which self-consciously examines the construction and perception of realities - some fictional, some theorised in cosmology. Valente's (b. 1979) roots as a writer lead to postmodernism and surrealism, but also to the popular forms of fantasy and the fairy-tale. Some of her works, like Palimpsest (2009) and stories of The Melancholy of a Mechagirl (2013) mix fantasy with contemporary urban settings and themes, whereas others, such as Orphan's Tales (2006-2007), A Dirge for Prester John (2010-2011), and Deathless (2011) draw more on historical and mythical elements. She is one of the foremost stylists of American sf, and even while her works have not been bestsellers, her name appears regularly on the awards lists, and in reviews she is usually commended for her precise sense for poetic language, for her willingness to grapple with the strange, and for the philosophical and metafictional themes she chooses (Alexander; de Zwaan; Wolfe).

Radiance is a series of films potted in a novel, where each of the films scripted, described or summarized in the text attempts to narrate the disappearance of the novel's central character. The setting is a dazzling version of our solar system in the best tradition of the planetary romance genre: think of the Barsoom books by Edgar Rice Burroughs, comics such as Flash Gordon, or films such as Forbidden Planet. Here Venus is a lush jungle, Neptune's methane seas are sailed by floating cities, the Plutonian pampas offer themselves to rugged frontiersmen, and the Moon houses the studios of a massive black-and-white film industry. Severin Unck, a documentary filmmaker famed for her unflinching presentation of both her own personality and of the darker sides of the societies she lives in, disappears while filming on Venus, and the novel consists of the official documents, memoirs and gossip-columns that lay out for readers the background to her life and death. We are also given the outlines, full scripts or narrativized versions of the many feature films that Severin's father, the movie mogul Percival Unck creates to try and represent what happened to her.

The novel's storyworld is also part of a quantum multiverse, where creatures known as callowhales are the only ones able to exist on the continuum of universes. One of these creatures

\footnotetext{
6 "Speculative fiction" is the now accepted umbrella term for science fiction, fantasy, and horror. The works Huber discusses in Literature after Postmodernism fall under mainstream fiction and maintain a mimetic frame around their fantastic elements (e.g. by presenting their narratives as found manuscripts), but within the speculative genres such a frame is not needed for the same effects to take place. See also Polvinen ("Sense-Making").
} 
gets sick and dies, and its death-throes penetrate through realities like a "cigarette burn" through film (Valente 427). That hole consumes, with no warning or explanation, first, the population of an entire village on Venus, and then Severin, who has arrived with her film crew to document what happened. After her inexplicable disappearance, Severin's father, known for over-the-top gothic romances and adventure films, sets out to manufacture a movie about her life in a desperate attempt to give his daughter and all the rest of the characters closure. Endings are what Percival Unck excels at:

If anything, I've always been too eager to get to the ending. I'll throw the haunted, wildeyed gamine from her tower too soon, slaughter a soliloquizing retinue complete with bicyclists and bears five minutes in. Endings are lush and lascivious . . . ; they call to me. All spread out on the satin of inevitabilities, waiting, beckoning, promising impossibly, obscenely elegant solutions. (38)

However, this time Percival fails at producing such an ending, and instead leaves us with fragments of different attempts at making a movie, each more fantastic than the other. The genres he reaches for in order to create this one more "obscenely elegant" ending include a hard-boiled detective story, a gothic screamer, a whodunnit and a fairy-tale. But each of the films is doomed to fail —not least because of the fundamental disagreement Percival and his daughter had about what films should be all about: attempting to grasp a documentarian's life through the means of fantasy may seem a fruitless endeavor to begin with. ${ }^{7}$

Readers of Valente's novel, however, discover that Severin was winked out by the eye of the dying of the callowhale she tried to film, and that she still has an existence of sorts in the interstices of the quantum multiverse, an existence that appears as fragments of film projected onto the bodies of an unnamed audience in a dark circus tent in the novel's prologue:

Look down. You can see a woman with dark hair and unhappy eyes moving silently on your bellies, your breasts, your thighs, your feet. Upside down, shorn of colour, flickering. Bent and cut up by the curves of your bodies and the age of the film. You see her as you see anyone in this world: distorted, warped, reflected, reflected, contorted, mutilated by time.

Radiance thus engages multiple realities both on the level of its storyworld (by including the quantum multiverse) and through the formal qualities of its narration (the metanarrative prologue as

\footnotetext{
${ }^{7}$ The novel is also about mothers: there is the secret of who exactly is Severin's mother, as the baby girl was left in a basket on the doorstep of Percy Unck's manor, and over the years each of the filmmaker's's seven successive wives was rumoured to be her birth-mother. Thus not only is Severin's end presented as a mystery, but so is her beginning.
} 
well as the multiple genres and text types used to represent storyworld events). ${ }^{8}$ At the center of Severin's disappearance is the hole seared through realities by the dying callowhale and the things left in its wake that do not belong: "Through such holes, other places seep and stain. Shards of those places stick in the wreckage of [the whale]. Songs you have never heard, movies you have never seen, words as unfamiliar as new planets. Other voices may cry through, orphan voices, unstuck from the mouths that made them" (406). These other realities become eerily present in the novel's world, even as Severin's absence is a hole that her father's films attempt to fill. And because these alternate worlds are, in all their patent unreality and outlandishness, compelling, and because the novel does not offer a solid storyworld ground to stand on, its readers are also drawn into the experience of shifting realities. This is particularly true of the prologue, where a voice like that of a circus crier speaks directly to the audience, inviting them in to the tent where Severin and the events of her story are projected onto their bodies.

Come forward. Come in from the summer heat and the flies. Come in from that assault on all senses, that pummeling of rod and cone and drum and cilia. Come in from the great spotlight of the sun, sweeping across the sands, making everyone, and therefore no one, a star. ...

It is dark inside the prologue. Dark and cool and welcoming. . . Let your eyes adjust. We need your eyes. Let the chartreuse pop of the sun's afterimage fade into the blackness we have thoughtfully provided. The floor creaks underfoot; slick, yielding wood, green as an olive in a martini, fresh from the forests of Ganymede. You can smell it lightly, under the lime polish. ...

But you will find no screen. You're it. (17-18)

However evocative this collection of embodiment and immersion effects is (covering the human sense palette from vision to sound and touch to smell), it is also blended with self-reflective references to a personified prologue, to changes in narrative fashions, and to the idea of the narrative itself as a space for readers to enter:

The prologue is patient. She has been told often that she is wholly unnecessary, a growth upon the story that the wise doctor must cut off. She has time and again found the doors to more fashionable establishments closed to her, while tables are set with candles and crystal for a top-hatted in medias res, a pedigreed murder at midnight, a well-heeled musical number. ...

\footnotetext{
${ }^{8}$ In Valente's own description, the novel is a “decopunk alt-history Hollywood space opera mystery thriller with space whales" (Jackson 2015).
} 
The prologue is where you take your coats off. Relax. Leave your shoes at the door. (1718)

Radiance therefore refuses to separate its storyworld from its own flamboyant artificiality, and asks instead its readers not only to enter the storyworld and be the bodies on which the narrative projects itself, but also to recognize and appreciate the flourishes by which that world is conjured for them, and the sensuality of the experience of giving up their bodies for the narrative artifice. From an enactive perspective, the affordances presented to us here at the novel's opening include both world-like qualities and self-reflective forms, and they are designed to prime readers to reach for both kinds of elements as they enact the novel that follows. This engages readers not just with the strange fictional world with its interdimensional space whales, but with the forms of language and conventions of representation that fiction relies on.

In Valente's novel the world and the artifice are thus both constantly present in the heady mixture of rip-roaring adventure across planetary environments and the self-consciously fragmentary and metaliterary form. The multitude of text-types sets readers in a struggle with source attributions: asking which version of Severin's father's film they are in, who is telling them what through which genre and for what purpose, and what to trust as true within this fictional universe and what to accept as invention. By narrating the main storylines with film scripts or cinematic voice-overs, and setting those in competition with formal interrogation transcripts or gossip columns about film stars, both of which claim to be eye-witness accounts of the events themselves, the novel also thematizes the debates concerning reliability of visual perception and narration, as well as those concerning fictional and non-fictional modes of representation. The fragments have a further, explicitly self-reflective function in examining the communicative role of the conventions of these genres and modes. For example, the recognizable science-fiction tropes of lunar colonies and rocket ships to Pluto are given a twist by the evocation of early $20^{\text {th }}$-century black-and-white cinema visuals - a look that is decidedly unrealistic to the audiences of present-day computer-generated science-fiction films. And when color appears, as it does in the first of Percival Unck's film versions, given to readers as a voice-over to a hard-boiled detective story, it does so in the lurid tones of technicolor fantasies:

\section{Case Log: 14 December, 1961}

It was closing in on midnight, the kind of midnight you only get on Uranus after a three-day bender. Ultramarine fog reeking of ethanol and neon and some passing whore's rosewater. Snow piled up like bodies in the street. Twenty-seven moons lighting up what oughta be a respectable witching hour so you can't help but see yourself staring back in every slick glowpink skyscraper. And the rings, always the rings, slashing down the sky, slashing down 
the storm, spitting shadows at the fella humping his carcass down Caroline Street, hat yanked down over his bloodshot eyes, coat hugged tight, shoes that need shining and a soul that needs taking in hand. (46)

The aim in such a paragraph is not just to set up the scene for readers - engaging their mind's eye in visualizing the glowpink skyscrapers and the ultramarine fog-but also to alert them to the presence of the genre conventions the narrative draws on (and sends up). Thus seeing is in this novel just as much a shorthand for experiencing literary form as it is for the construction of visual images in our minds.

It should be underlined that despite the manifest invention involved, Valente's novel shares with Huber's more mainstream reconstructive fantasies a refusal to abandon either emotional sincerity or the pragmatic power of fiction. Radiance is a novel about family, about love and loss, and about the ways in which human beings form connections with each other despite the wildly differing experiential worlds they occupy. "This is a story about seeing. This is a story about being seen," the novel declares and refers not only to the multiple quantum worlds (that come into existence in the act of "seeing" or measurement) or the perception of literary form, but also to the characters' attempts to acknowledge, recognize and communicate with each other. Nor are readers, as the audience who have allowed their embodied minds to become the screen for this narrative, expected to remain untouched. Engaging with invention - even with the inconsequential magic of planetary fantasies - has its effects, the novel claims, just as the seemingly weightless light of this narrative, projected by the prologue, has effects on the bodies of its audience:

Light has no personal temperature. But your body knows instinctively that light is cold. The idea of light, the narrative of light. Light will chill you blue. The trickster hemispheres of your brain insist that the flickering images do have weight; they press on you like greyscale fingers, corpse fingers, angelic fingers, unworlded hands. The touch of images alters you-it must, it cannot help but. And more than touch you, these pictures, these maps of illumination enter you. Photons collide with flesh; most reflect, some penetrate. (112) So this novel is about being seen by the people around us, even as it also is, self-reflexively, about perceiving a fictional world, and about what it means for human beings to see and be impressed by the ephemeral forms of story; in other words, it is about how narrative fiction uses cognitive affordances to project on its readers countless possible and impossible experiences. The trope of film allows Radiance to talk about flickering, uncertain realities while still keeping its eye on the embodied perception of fictions and on the communicability of worlds, both of which are central to $21^{\text {st }}$-century reconstructive fantasies. In cinema, the flickering effect on the screen results from the individual frames of the film that blend in our perception into the seemingly seamless moving 
image, but Radiance turns its attention to what can be seen on the screen while still experiencing the flicker of the individual frames. It is this sensation of our acts of embodied perception mixing in with a world of fragments that constitutes the eerie of reconstructive fantasy; a sensation that "is achingly alluring even as it is disconcertingly alien" (Fisher 81).

\section{Conclusion}

The landscape of affordances we exist in — both when we navigate reality and when we engage with a work of fiction - involves both absences and presences that are on a fundamental level unstable. In this article I have suggested that taking on board the eeriness of enactive cognition helps in conceptualizing the ontological structures of contemporary reconstructive fantasies. The worlds of these narratives feel like they are physically present (when of course they are not) and the formal qualities are not physically present (even when they affect us as if they are). These eerie environments share with postmodernist fiction their interest in unstable realities, but at the same time they are committed to what Huber calls the pragmatic, communicative structures of fiction. Thus, while it might seem that ontological hesitation lessens the impact of these narratives on realworld issues, it is in fact precisely in their willingness to engage with the instability of worlds that these fictions can help us understand our entanglement with the complexity of our real-world environments.

The second line of my argument has engaged cognitive literary studies, where the theorizing of fictional worlds tends to obscure the formal qualities in works of fiction, or at least subsume them to the immersive in readerly experience. By drawing on the eerie I therefore also want to make the point that cognitive theories about the experience of fictional worlds need to be able to better accommodate the artificiality of a fictional narrative- the presence of generic, conventional, and stylistic affordances in the landscape we navigate in reading. According to Gibson's ecological psychology, human beings are capable of creating perceptual artifacts that are not primarily meant to convey information, but instead "[perceivable] structure as such can be invented by artifice"; that is, structure that "affords perception but not perception of" (Heft 132-133; citing Gibson's The Senses Considered as Perceptual Systems, 1966). Fictions, I suggest, are cognitive environments not in the sense of readers enacting just the world represented in the text, but instead in the sense of readers enacting an abstract cognitive space where artifice, figuration and narrative structure are also part of the environment (see also Cave; Kortekallio). This is particularly true of Valente's Radiance, which places its readers in an enactive, constitutive relationship with its own artifice. The emotional themes of family, love, recognition, and loss are brought forth by the eeriness of 
flickering realities, and seeing is presented as an act of co-creating, rather than just taking in, a reality. The novel thus continues the postmodern tradition of disturbing ontological borders, but does so in the context of reconstructive fantasy. There is no anxiousness to the hesitation over what is reality, but rather a celebration of the power of fiction to reshape realities - and therefore ourselves - by affording readers the chance to experience formal qualities of writing as those of an environment, even as they imagine the writing as sensory experiences of the fictional world. The two aspects of fiction — world and artifice — are both there for the readers' embodied perception, but one eerily failing to be absent, and the other equally peculiarly failing to be present.

\section{Works Cited}

Alexander, Niall. “The Light Fantastic: Radiance by Catherynne M. Valente.” Tor.com, 3 March 2016. https://www.tor.com/2016/03/03/the-light-fantastic-radiance-by-catherynne-mvalente/. Accessed 26 June 2020.

Attebery, Brian. "Structuralism." The Cambridge Companion to Fantasy Literature, edited by Edward James and Farah Mendlesohn, Cambridge UP, 2012, pp. 81-90.

Bell, Alice and Jan Alber. "Ontological Metalepsis and Unnatural Narratology.” Journal of Narrative Theory, vol. 42, no. 2, 2012, pp. 166-192.

Bernaerts, Lars. "The Blind Tour: Spatial Abstraction in Experimental Fiction." The Stylistics of Landscapes, the Landscapes of Stylistics, edited by John Douthwaite, Daniela Francesca Virdis and Elisabetta Zurru, Benjamins, 2017, pp. 61-79.

Caracciolo, Marco. "Ungrounding Fictional Worlds: An Enactivist Perspective on the 'Worldlikeness' of Fiction." Possible Worlds Theory and Contemporary Narratology, edited by Alice Bell and Marie-Laure Ryan, U of Nebraska P, 2019, pp. 113-131.

---. "Weird Shimmers." Collateral, vol. 16, 2019. http://collateraljournal.com/index.php?cluster=16. Accessed 15 January 2020.

Cave, Terence. Thinking with Literature. Oxford UP, 2017.

Clark, Andy and David J. Chalmers. "The Extended Mind.” Analysis, vol. 58, no. 1, 1998, pp. 7-19.

de Zwaan, Victoria. “Old Scripts, Contemporary Versions.” Review of Catherynne M. Valente's Six-Gun Snow White. Los Angeles Review of Books, 13 March 2013. https://lareviewofbooks.org/article/old-scripts-contemporary-versions/. Accessed 26 June 2020.

Di Paolo, Ezequiel. "The Enactive Conception of Life." The Oxford Handbook of 4E Cognition, edited by Albert Newen, Leon De Bruin and Shaun Gallagher, Oxford Handbooks Online 2018. DOI: $10.1093 /$ oxfordhb/9780198735410.013.4

Fisher, Mark. The Weird and the Eerie. Repeater, 2016.

Gibson, James J. The Ecological Approach to Visual Perception. Houghton Mifflin, 1979. 
Heft, Harry. 'Perceptual Information of 'An Entirely Different Order': The 'Cultural Environment' in The Senses Considered as Perceptual Systems." Ecological Psychology, vol. 29, no. 2, 2017, pp. 122-145.

Hodder, Ian. Entangled: An Archaeology of the Relationships between Humans and Things. WileyBlackwell, 2012.

Huber, Irmtraub. Literature after Postmodernism: Reconstructive Fantasies. Palgrave Macmillan 2014.

Jackson, Matthew. "The Mystery of the Missing Filmmaker: Interview with Catherynne M. Valente.” BookPage, 20 Oct. 2015. https://bookpage.com/interviews/18969-catherynne-mvalente-fiction. Accessed 27.6.2020.

Kortekallio, Kaisa. Reading Mutant Narratives: The Bodily Experientiality of Contemporary Ecological Science Fiction. Doctoral dissertation, University of Helsinki, 2020.

Kramnick, Jonathan. Paper Minds: Literature and the Ecology of Consciousness. U of Chicago P, 2018.

Kukkonen, Karin. "Fantastic Cognition.” Cognitive Literary Science: Dialogues between Literature and Cognition, edited by Michael Burke and Emily T. Troscianko, Oxford UP, 2017, pp. 151-167.

Maturana, Humberto and Francisco Varela. Autopoiesis and Cognition: The Realization of the Living. 1972. Boston Studies in the Philosophy of Science 42. Riedel, 1980.

McHale, Brian. Postmodernist Fiction. Routledge, 1987.

Merleau-Ponty, Maurice. Phenomenology of Perception. 1945. Translated by Donald A. Landes. Routledge, 2012.

Newen, Albert, Shaun Gallagher and Leon De Bruin. "4E Cognition: Historical Roots, Key Concepts, and Central Issues." The Oxford Handbook of 4E Cognition, edited by Albert Newen, Leon De Bruin and Shaun Gallagher, Oxford Handbooks Online 2018. DOI: 10.1093/oxfordhb/9780198735410.013.1

Polvinen, Merja. "Enactive Perception and Fictional Worlds." The Cognitive Humanities: Embodied Mind in Literature and Culture, edited by Peter Garratt, Palgrave Macmillan, 2016, pp. 19-34.

---. "Sense-Making and Wonder: An Enactive Approach to Narrative Form in Speculative Fiction." The Edinburgh Companion to Contemporary Narrative Theories, edited by Zara Dinnen and Robyn Warhol, Edinburgh UP, 2018, pp. 67-80.

Rietveld, Erik, Damiaan Denys and Maarten Van Westen. "Ecological-Enactive Cognition as Engaging with a Field of Relevant Affordances: The Skilled Intentionality Framework (SIF)." The Oxford Handbook of 4E Cognition, edited by Albert Newen, Leon De Bruin and Shaun Gallagher, Oxford Handbooks Online 2018. DOI: 10.1093/oxfordhb/9780198735410.013.3

Thompson, Evan. "Sensorimotor Subjectivity and the Enactive Approach to Experience." Phenomenology and the Cognitive Sciences, vol. 4, 2005, pp. 407-427.

Todorov, Tzvetan. The Fantastic: A Structural Approach to a Literary Genre. 1979. Translated by Richard Howard. Cornell UP, 1973.

Valente, Catherynne M. Radiance. Tor, 2015. 
Varela, Francisco J., Evan Thompson and Eleanor Rosch. The Embodied Mind: Cognitive Science and Human Experience. 1991. MIT Press, 1993.

Walsh, Richard. "Fictionality as Rhetoric: A Distinctive Research Paradigm." Style, vol. 53, no. 4, 2019, pp. 397-425.

Wolfe, Gary K. Review of Catherynne M. Valente's Space Opera. Locus, vol. 688, 2018, p. 17. 